\title{
Investigation and type analysis of traditional residential buildings in Qinghai section of "Silk Road"
}

\author{
LI Yan-jun ${ }^{1, *}$, HUANG Jing-fan ${ }^{2}$ \\ ${ }^{1}$ Faculty of design and art, Shaanxi university of science and technology, Xi'an 710021, China \\ ${ }^{2}$ Faculty of art and design, Xi'an university of technology, Xi'an 710054, China
}

\begin{abstract}
This paper takes the traditional residential architecture culture of Qinghai section of the land Silk Road culture as the breakthrough point. A large number of historical materials and unearthed cultural relics show that Qinghai section is an important channel of the south line of the ancient Silk Road and an important part and key node of the silk road. However, in the long-term use of local residential buildings, due to the lack of reasonable protection, as the only physical carrier of research and construction technology, it is gradually disappearing around people. Based on the image data collection and cultural background search of the current situation and types of residential buildings along the Silk Road in Qinghai Province, the author summarizes, combs and researches the data of different types of buildings, focusing on the morphological characteristics of residential buildings in different regions and nationalities. Firstly, the author summarizes the natural and cultural environment along the line, and analyzes the distribution characteristics of residential buildings combined with the regional environment background; Secondly, according to the survey records, the paper combs the protection status of residential buildings and the influencing factors of residential buildings, aiming to put forward the thinking path for the later protection and inheritance of residential architectural culture; Finally, along the regional line, the paper explains the national ownership, material selection and architectural characteristics of the residential buildings in each natural area, and summarizes the influencing factors of the residential buildings in the three natural areas along the line, as well as the architectural characteristics of the main types of buildings, such as quadrangles, Zhuangkuo residential buildings, fence buildings, tents and yurts. The purpose of this paper is to supplement and improve the research results of the cultural system of traditional dwellings in Qinghai section of the silk road.
\end{abstract}

\section{Preface}

The silk road passes through Shaanxi, Gansu and Qinghai provinces, Ningxia Hui Autonomous Region and Xinjiang Uygur Autonomous Region. The overall route is divided into eastern and Western sections. The eastern section is further divided into three branches, namely north, middle and south. The Qinghai section is the main part of the southern branch, which specifically refers to the ancient road connecting with the west section of the main road of land transportation between China and the west through Huangshui River Basin, Qinghai Lake and Qaidam Basin ${ }^{[1]}$. According to a large number of historical materials and unearthed cultural relics, Qinghai is the main road of the southern route of the ancient Silk Road. This road starts from Linxia today and reaches Hainan, Haixi, Mangya and Ruoqiang in Xinjiang via Xining. It joins with the main road of the Silk Road and leads to the Western Regions. It is a trunk line of the ancient Silk Road from the sixth century to the first half of the ninth century ${ }^{[2]}$. As one belt, one road culture has great influence on the world, the development of civilization, commerce and trade, and cultural exchange, the study and protection of the culture along the line can make people and people along the way more comprehensive in understanding their traditional culture and customs, so as to enhance their cultural identity and conspire to "one belt and one road" development initiative. Realize the "Chinese dream". Traditional dwellings and villages record people's life and production mode in different areas for thousands of years, and they are living fossils of historical and cultural development ${ }^{[3]}$. However, due to long-term use and natural weathering, coupled with the lack of reasonable maintenance and protection, residential buildings, as the only physical carrier for the study of construction technology, are gradually disappearing around people ${ }^{[4]}$. Therefore, it is urgent to carry out rescue data collection and protective research on traditional residential buildings in various areas along the line.

In this paper, only the existing representative traditional residential buildings in Qinghai Province were investigated and recorded, which laid the foundation for the follow-up research.

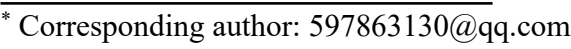




\section{Overview of regional environment and residential distribution}

\subsection{Regional environment background}

Qinghai section along the silk road has very rich survival wisdom in residential buildings due to its special geographical location and diverse ethnic composition ${ }^{[5]}$.

From the perspective of landform, the landform types in eastern Qinghai are relatively complex, including mountains, basins, hills, valleys and deep canyons. Under special geographical conditions, there are relatively more mountain forests, rivers and loess resources, which provide wood, stone, loess and other sources of building materials for residential buildings. The central and western regions are relatively flat, with grassland, basin, desert, shallow hills and other topographic features, which are suitable for the development of nomadic industry. From the geographical location of residential distribution, traditional villages mainly exist in three geomorphic types of plain, shallow hills and high mountains and valleys $^{[6]}$. Local residents are based on the natural geographical conditions, comprehensive climate, altitude, precipitation, wind direction, sunshine time, local building materials and other factors for technical construction, showing a variety of architectural forms in terms of architectural form, construction $t$ echnology and material selection.

From the perspective of ethnic composition, Qinghai is a multi-ethnic province. In addition to the Han nationality, there are 53 ethnic minorities, such as Tibetan, Hui, Mongolian, Tu, salar, etc., and the minority inhabited areas account for $98 \%$ of the total area of the province ${ }^{[7]}$. Due to the different national historical traditions and cultural heritage have their own characteristics, gradually formed the characteristics of today's Qinghai cultural symbiosis. As a part of national material and non-material culture, under the influence of multiple residential folk culture, local residents divide the functions of buildings according to the needs of production and life. Different nationalities have their own uniqueness in housing, furniture, tools, customs, habits and so on.

From the perspective of geographical distribution, Qinghai has changed from farming civilization to nomadic civilization from east to west. Riyue mountain in the east of Qinghai Lake is a natural dividing line of agriculture and animal husbandry, with agricultural areas in the East, animal husbandry areas in the west, and farming and pastoral areas crossing each other in the middle. From the perspective of residential form, according to the differences of nationality, natural environment and life style, the typical residential building types are formed, such as Zhuangkuo residential building, fence building, Gobi oasis residential building, activity tent and so on. By region, from east to West are Hehuang region in the East, Huanhu and surrounding pastoral areas in the middle, and Qaidam region in the West.

\subsection{Distribution of residential buildings}

Qinghai has a vast area and a small population density, but its spatial distribution is not balanced, showing a sparse distribution in the East. The soil, climate, precipitation and other natural conditions in the eastern region are suitable for farming, and can undertake the monsoon surplus. It is the region with the best natural conditions and living conditions in Qinghai, with convenient commerce, transportation, high accessibility, rapid economic development, and suitable for living. Therefore, the population is also the most concentrated, and the residential buildings are also relatively dense, especially in Xining and Haidong. According to the statistics at the end of 2019, there are 4144 Village Committees (administrative villages) in Qinghai Province. The villages are mainly concentrated in Xining city and Haidong city. The total number of villages in the two cities is higher than the sum of the number of villages in the other six autonomous prefectures ${ }^{[8]}$. The central and western regions are characterized by vast land and sparse population. Due to the influence of natural factors such as drought, less rain, low temperature and cold, the development of agriculture is limited, mainly relying on animal husbandry, coupled with low traffic accessibility and relatively limited economic development channels, resulting in a small population density in the western region. From the perspective of population spatial density distribution, the number of residential buildings in the eastern region will be more than that in the central and western regions, showing a decreasing trend from east to west.

\section{Analysis of the current situation and influencing factors}

\subsection{The present situation of residential preservation}

In recent years, the Chinese government has issued cultural protection policies for traditional culture and intangible cultural heritage. Ancient villages, typical national buildings and rural residential folk culture in towns and townships have been included in the scope of protection. In Qinghai Province, a total of 79 villages have been rated as Chinese traditional villages. As a result, the government officials and the common people are increasingly aware of the protection of traditional culture. However, in terms of the total number of existing buildings, the old buildings are becoming more and more rare due to various reasons. Even some large and relatively complete traditional villages have been completely demolished. The rich and colorful regional residential features covering construction technology and art information have been gradually replaced by the modular construction of new countryside, and the number of traditional residential buildings has been reduced year by year ${ }^{[10]}$. Fortunately, in the remote rural areas with low accessibility in Qinghai, some rural dwellings that integrate production, life and natural environment are still preserved, such as Lunan village, 
Nuomuhong Township, Dulan County, Da zhuang village, Xunhua Salar Autonomous County, Xiela village, Xinger Township, Hua long Hui Autonomous County. However, from the perspective of architectural heritage protection, although these rural dwellings retain the original architectural structure and appearance, due to the lack of repair, obvious safety problems have appeared, affecting the normal life of residents. Some of the dilapidated buildings failed to continue to use the traditional building materials and technology, and the traditional construction technology has not been continued and inherited in the process of repair. It can be seen that the traditional villages and towns in most areas of China are facing the contradiction of protection, renewal and development ${ }^{[11]}$. Only when a professional team is in charge of guidance and macro control can the chaos be turned into a correct method of repair and reconstruction.

\subsection{Analysis of damage causes}

First of all, the structure of traditional residential buildings in Qinghai is civil engineering. Due to the influence of natural climate and environment, the wood is extremely short. The forest coverage rate of Qinghai Province is only $0.26 \%$, about 2.5 million $\mathrm{mu}$, and the distribution is scattered ${ }^{[12]}$. Because of the vulnerability of its materials, it is vulnerable to the destruction of natural conditions such as wind sand, high temperature and low temperature. Secondly, the local residents also lack systematic theoretical guidance and technical support for the restorative protection of traditional buildings. At the same time, in the face of the new era of rapid development of cities and towns, the network information is more diversified. In addition, rural areas respond to the call of the country and vigorously develop rural construction. However, the rapid and blind rural construction makes the rural buildings in various regions become the same, and the phenomenon of "one village for one" has lost the original local flavor and architectural characteristics ${ }^{[13]}$. More and more new building materials are applied to the construction of residential buildings, which makes the traditional way of living unable to meet the local residents' pursuit of modern lifestyle. In particular, the number of craftsmen in the field of residential construction technology, which is inherited by the master and apprentice, father and son, is decreasing, forming a cliff like demise of craftsman and regional cultural characteristics of traditional residential buildings. In view of the current situation, the author summarizes and analyzes the reasons for the declining number of traditional dwellings from seven aspects: natural conditions, personnel loss, cultural and tourism development, policy support, security, construction technology inheritance and production and lifestyle.

\subsubsection{Natural condition}

- Qinghai has long sunshine time, large evaporation and strong radiation. As one of the main building materials, wood is mainly concentrated on the shady slope of the mountain, and the vegetation coverage is rare. Due to the terrain of Qinghai, the vegetation is extremely short and scattered.

- Affected by natural weathering, the wind speed in Qinghai can reach more than $3 \mathrm{~m} / \mathrm{s}$ in the western Qaidam region. The cold winter wind blows directly into the Hehuang valley through the flat grassland of Qinghai Lake, along the East-West alpine mountains. Although the wind speed has weakened, it also reaches $1.6 \mathrm{~m} / \mathrm{s}^{[14]}$. Therefore, the land desertification is serious, which leads to the rammed earth dwellings are not solid and easy to collapse.

\subsubsection{Loss of personnel}

- A large number of residents move to the city, and the original rural civil buildings are seriously weathered after many years of non residence, which will lead to weathering and collapse. Because it is a civil structure, the repair needs to consider the problems of fire prevention, shockproof, anti weathering, and the production of the original old craft building materials is very little and expensive. The maintenance cost is high, which leads to no repair.

\subsubsection{Cultural tourism development}

- With the development of tourism economy, the originally closed rural settlement environment has been opened. A large number of tourism developers use the gimmicks of Qinghai tourism city to carry out product packaging for rural settlements, in order to obtain tourism economic benefits, and lose the local original style and characteristics.

- The ecological structure of Qinghai is fragile and it is a tourist city. In order to pursue the interests, the developers did not survey the local real geological conditions, and wantonly used the ecological resources in the development process, which damaged the original geological image and structure.

\subsubsection{Policy support}

- The cultural tourism management department started the protection of traditional residential buildings and folk culture late, failed to keep the original images, construction technology and data in time, and lost the construction techniques, so it is difficult to continue to inherit the original traditional culture $100 \%$.

- Macroscopically, there are some policies to support and embody. However, there is often no financial support, which makes the buildings in urgent need of repair collapse and damage without timely support.

\subsubsection{Security}

- It is good for the central government to beautify the countryside for the sake of beautiful countryside, transform the old villages and ensure the people's living safety. However, at the grass-roots level, all the old 
houses have been demolished, and the relationship between "protection" and "demolition" has not been properly defined. It is a pity for those who are committed to the protection and inheritance of traditional culture.

- Most of the traditional building materials are soil, wood and stone, which have no advantages like reinforced concrete and brick materials in terms of fire prevention, moisture-proof, weathering resistance, earthquake resistance and other stability. The safety factor is relatively low, and it is easy to collapse without repair for a long time.

\subsubsection{Create technology inheritance}

- There is a fault in the inheritance of traditional construction technology. A large number of local young people blindly pursue the modern life of urbanization and are unwilling to learn, inherit and work on the unique construction techniques of nationalization, resulting in the phenomenon of no successor, which greatly reduces the sense of cultural identity.

- With the rapid development of new materials, mechanized construction and convenient transportation, new building materials and mechanized construction methods continue to flow into the western region, and the construction of residential buildings has changed from manual to mechanized. Skilled craftsmen are hard to get jobs and cannot support their families.

\subsubsection{Production and lifestyle}

- With the Internet entering into thousands of households in the western region, people have more and more access to external information and culture, which makes the local residents' aesthetic concept and cultural identity gradually fade. The regional culture presents a trend of simplification, and it is difficult to maintain and retain the national characteristics.

- The traditional way of production and life has been difficult to meet the needs of local residents, people have a higher level of pursuit of life, yearn for comfortable and convenient urban housing, and hope to give their children good education resources and other practical reasons, which makes the traditional residential buildings and residential folk culture gradually replaced by the modern way of production and life.

\subsection{Analysis of reasons for retention}

The Qinghai section of the silk road is more than 1200 kilometers from east to west. The areas with high accessibility are concentrated in the East and around the lake areas. Due to the low accessibility in some remote villages in the central and western regions, the traditional residential folk culture is relatively well preserved, and the retention rate of residential buildings is relatively high. According to the investigation and interview, the reason why these traditional residential buildings are still living is mainly due to their survival wisdom accumulated according to the natural conditions, and they are good at using local materials and terrain. The author mainly summarizes the reasons why the existing traditional dwellings have survived from three aspects: survival wisdom, policy support and family memory and feelings.

\subsubsection{Survival wisdom}

- In the construction of residential buildings, the natural geographical conditions are fully considered, the local building materials are used, the construction techniques and building forms are combined with the climate, precipitation, wind direction, sunshine time, natural energy conversion, etc., which are evolved after thousands of years of improvement. The building form is the best form of adjusting measures to local conditions and the unity of nature and man, which is the embodiment of the survival wisdom of the ancestors. At the same time, due to mature construction technology, good durability and long-term habitation, more buildings are left.

\subsubsection{Policy support}

- Although the cultural protection work of the government started late, it has attached great importance to the protection of the unique folk culture of ethnic minorities, and has maintained a high degree of consistency with the relevant documents of the central government in terms of policy, so as to implement the support objects. The villages with high preservation integrity are protected as traditional ancient villages and registered at the same time. This provides a basis for the follow-up systematic research.

- The economic development of some remote areas is relatively backward, and some areas and residents have not yet completed the signing of housing subsidy agreement.

\subsubsection{Family memory and feelings}

- Each nation has its own living folk culture and habits. The functional needs of rooms are divided according to different cultural beliefs and production and life needs. The new residential buildings can not meet their traditional habits and production and life needs.

- As the folk house carries the family tradition and good memories of a family, once it is demolished, the family tradition will become the past. Therefore, the local residents can seal up and continue their emotions, and retain the unique residential folk culture of the nation and family. And after many years of living, has been used to the original way of life, so the use of repair rather than demolition. 


\section{Analysis of residential building types and regional characteristics}

\subsection{Types of residential buildings along the line}

Under the influence of multiple folk culture, national beliefs, production and life style of human environment and natural conditions of low cold climate, large temperature difference, less drought and precipitation, Qinghai presents a variety of residential building forms in terms of building form, construction technology, material selection, etc. It is obvious that in the east of Riyue mountain in Qinghai Lake, due to agricultural production, the residential buildings are relatively fixed. The central and western regions to the west of Riyue mountain are mainly nomadic. Due to the need to choose suitable pasture according to the season for cattle and sheep, the houses are detachable and easy to move. According to the region, ethnic distribution, residential types and building materials along the line, the author combs and shows the representative residential buildings in each region from east to west along the line, and lists the different architectural forms presented according to the needs of production and life (see Table 1).

Table 1. Types of traditional residential buildings

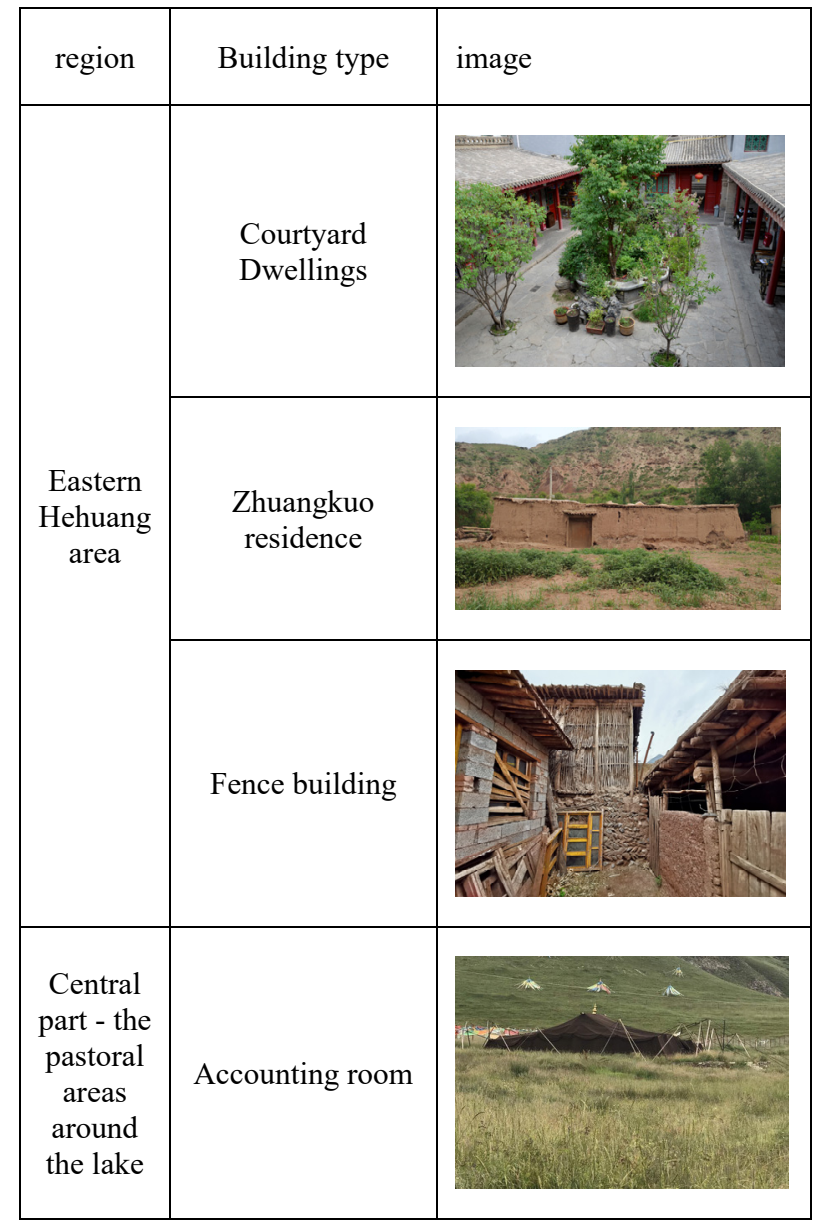

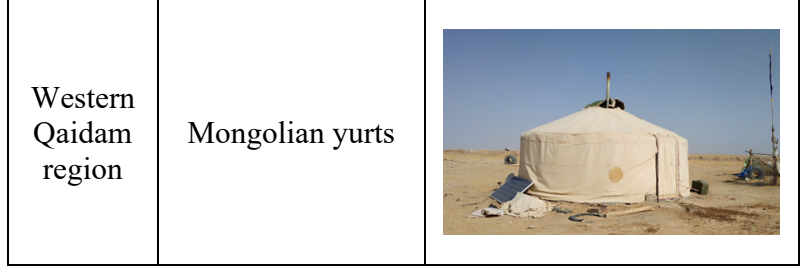

\subsection{Regional characteristics of residential buildings}

The most prominent feature of Qinghai residential buildings lies in its rich cultural connotation and diversified forms. From a historical point of view, there are many ethnic groups along the ancient Silk Road in Qinghai, and their religious beliefs and living customs are quite different. With thousands of years of large mixed living and small concentrated living pattern, their cultures continue to infiltrate and integrate with each other, forming a unique local ethnic cultural pattern ${ }^{[9]}$. This pattern is mainly due to the great differences in the natural environment, production and lifestyle, and the convergence, tolerance and integration of different national cultures. This diversified national cultural pattern is prominent in the field of residential architecture, not only among different nationalities, but also within the same nationality. Even the residential architecture of the same nationality has different construction methods, material selection and architectural forms in different regional environments, which is a survival strategy adopted by various nationalities in response to the regional natural environment, With the passage of time, the architectural culture of our nation has gradually formed ${ }^{[6]}$. It can be said that the representative architectural forms in various regions are created by the residents in adapting to the local geography, climate and other natural environment, and in order to survive and constantly improve and perfect.

From Hehuang area in the East, around the lake and surrounding pastoral areas in the middle to Qaidam area in the west, there are obvious differences in regional economic development level, residents' production and life style, ethnic distribution, cultural identity and living physical and geographical conditions, which will have an impact on the choice of architectural form. For example, in the eastern region, due to the large population, ethnic diversity and frequent wars in history, the distribution of residential buildings is relatively compact, and the periphery of the buildings is surrounded by high and thick walls, which can resist the cold and defend against the cold. However, in the central and western regions, due to the nomadic production mode and the frequent migration according to the seasons, the walls of nomadic areas are not common, and the tents are easy to migrate.

\subsubsection{Eastern Hehuang area}

The word "Hehuang" was first found in the biography of Xiqiang in the book of the later Han Dynasty, in which there is a record of "Naidu Hehuang, Zhuling jusai". 
Hehuang here refers to the Yellow River and its tributary Huangshui at the junction of Gansu Province and Qinghai Province. Now it mainly refers to the "Three River area" composed of the upper reaches of the Yellow River, Huangshui River Basin and Datong River Basin. Its geographical scope includes the east of today's Yueshan mountain, the South of Qilian Mountain, four districts and three counties in Xining, Haidong and Hainan Huangnan and other places along the river and Linxia Hui Autonomous Prefecture of Gansu Province [16]. In Hehuang area, in order to survive and develop, different ethnic groups cooperate with each other in the field of production and life, especially the animal husbandry ethnic groups. Their dependence on agriculture and commerce makes them naturally have the ability to adapt to the interdependence with other ethnic groups, and also have the consciousness of absorbing and digesting other ethnic cultures on the basis of their own culture [17]. Hehuang area is a transitional area between Central Plains and western minority areas, and between agricultural culture and animal husbandry culture. The most prominent feature is the diversity of nationalities. The Han nationality is the main ethnic group. The five major ethnic minorities are distributed here, showing the characteristics of large dispersion, small settlement and mixed residence. The main building types are quadrangle, Zhuangkuo residence and fence building, The most representative residential building with the highest utilization rate is Zhuangkuo residential building. On the one hand, Zhuangkuo residence absorbed the architectural form characteristics of Han style, which is the most common evolution form of courtyard architecture in Central Plains. On the other hand, it has obvious Western characteristics in the use of building materials. Taking soil, stone and wood as the main building materials, all residential buildings adopt rammed earth wall (earth wall, earth yard), adobe house and earth flat roof house, which are integrated with the environment.

\subsubsection{Central Lake and surrounding pastoral areas}

Around the Qinghai Lake and the surrounding pastoral areas, the ethnic groups are mainly Tibetan and Mongolian, with cattle and sheep as the main mode of production. In order to facilitate migration, tent is a necessary living utensil for nomadic people, and it is also one of the main architectural forms of local dwellings. The local tents can be divided into winter and summer according to seasons, and the use combination can be divided into primary and secondary. Yak hair tent is used in winter. It is woven from yak hair and has strong cold resistance. Meanwhile, yak hair has good air permeability in the sun. It can absorb the heat of the sun for heating in the daytime. There is a skylight on the top of the tent for ventilation, lighting and smoke. It can be covered in rainy days. In order to play a good role in fixing and preventing wind and snow erosion, the bottom of the tent does not directly fall to the ground, and the gaps are sealed with soil blocks or stones built into low walls. There is a stove in the center of the accounting room, one can be used for heating, the other can be used for cooking food, milk tea, etc. Cloth tent is used in summer. Now the common cloth tent is colorful, and its decorative patterns and colors are regular. The lower part is surrounded by a blue frill, the middle part is decorated with red, yellow and green patterns, and the upper part is decorated with white beads on a black background. Cloth tent is light and easy to carry when going out for a short time. On the other hand, it can also be used for temporary residence when the main tent is not enough. The Mongolian yurt is made of wool felt, which is also easy to disassemble and has good windproof and warm keeping effect. Therefore, tent, yurt, which are easy to move, easy to load, unload and transport, become the main representative of plateau residential buildings.

\subsubsection{Western Qaidam region}

Qaidam is a sparsely populated area with Mongolian and Kazak nationalities, scattered in Dulan, Golmud, utumeren, Mangya, Ulan, Delingha, Dachaidan and other areas. Before the founding of new China, these ethnic groups lived on animal husbandry, lived along the water, lived a nomadic life, and had little agricultural production. After the founding of new China, especially in Golmud area, with the rapid economic development of Lycium barbarum and other agricultural products and the influx of farmers, the effect of land desertification control was remarkable, and the fixed residential buildings similar to the eastern agricultural area gradually appeared, that is, the simplified village outline and diwozi buildings.

To the west of Golmud, the main dwellings are yurts. The most fundamental ecological philosophy wisdom of nomads is to follow the ecological law of grassland and the concept of green development. Local herdsmen play the role of ecological regulator in the western grassland, consciously serve for the protection and restoration of grassland natural environment and the normal operation of ecosystem, and promote the sustainable survival and development between human society and grassland ecological environment ${ }^{[18]}$. Yurts are divided into two types: the fixed type in semi farming and semi pastoral areas and the mobile type in nomadic areas. The building materials used by the two types are different, but they tend to be the same in shape and internal division. The Mongolian yurt has a round viewing angle. It is surrounded by strips of wood woven into a network, which is surrounded by a cylinder. The conical dome is connected with the external facade. The tent top and its surroundings are covered or surrounded by felt, which is fixed with ropes. The side wall is installed with door panels. A circular skylight is left on the tent top for lighting, ventilation and smoke discharge. In rainy weather, felt can be used to cover it ${ }^{[19]}$.

\section{Conclusions}

The development strategy of the Silk Road Economic Belt implemented by the state provides a new opportunity for the development of Tourism along the 
Silk Road, which can promote the development of local economy and Tourism along the route to a certain extent, and establish the tourism image and status of Qinghai section of the Silk Road in the whole country and even the world ${ }^{[20]}$ This paper will carry on the series arrangement and display of the traditional residential building form, leaving rich historical data and research results for the local people, and make the people more comprehensive understand the traditional culture, national culture and living customs along the silk road. In addition, Qinghai Folk Residence Architecture has distinct diversity and national characteristics because of the common life and cross living of many nationalities. The diversity is a survival strategy adopted by all ethnic groups to cope with the natural environment of the region from the perspective of cultural ecology, and it is also a survival strategy adopted by all ethnic groups to adapt to nature, adapt to nature and adapt to local conditions, Evidence of showing intelligence. The types of residential buildings along the line include Siheyuan, zhuang'an residence, fence building, cattle hair tent house and Mongolian bag. The main ethnic groups are Han, Hui, Tibetan, Sala, Tu and Mongolian. The paper can guide and draw lessons from the scientific and effective protection and inheritance of the preserved buildings. It calls for urging local governments and relevant competent departments to put forward practical solutions for the protection of traditional houses, so that these buildings and folk culture with strong regional and national characteristics can be protected and inherited.

\section{Acknowledgments}

This paper is one of the phased achievements of the National Social Science Fund's 2018 key project Research on the architectural art and folk culture of Chinese traditional dwellings in the land 'Silk Road' (Approval number: 18AH008)

\section{References}

1. Local chronicles Compilation Committee of Qinghai Province. Chronicles of Qinghai on the Silk Road $[\mathrm{M}]$. Qinghai Nationalities Publishing House, 2017.12:2

2. Yang Ziyan, deputy director of the Propaganda Department of the provincial Party committee. Qinghai's position in the Silk Road Economic Belt [N]. Qinghai daily, April 28, 2014 (006)

3. Ma Ke, Li Yanjun. On the spatial layout of Mizhi traditional kiln village $[\mathrm{J}]$. Popular literature and art, 2013 (23): 139-141

4. Zhang Nenjiang. Research on construction technology and inheritance of traditional Zhuangkuo dwellings in eastern Qinghai [D]. Xi'an University of architecture and technology, 2016

5. He Xiyan. A historical review of Qinghai folklore [J]. Journal of Qinghai Normal University, normal college for nationalities, 2014,25 (02): 38-42
6. Cui Wenhe. Study on the renewal suitability design mode of local dwellings in Qinghai multi ethnic areas [D]. Xi'an University of architecture and technology, 2015

7. Chen Rong, Ma Yaofeng. Spatial distribution pattern and influencing factors of traditional villages in Qinghai Province [J]. Qinghai Social Sciences, 2019 (06): 239-244

8. Jin Yibing, Jia Mengting, Li Simin. Research on rural landscape in Northwest China [M]. China Construction Industry Press, 2019.1:24-25

9. Li Shurui. Research on the multicultural development of Qinghai Road on the Silk Road [J]. Qinghai Social Sciences, 2020 (01): 48-54

10. Ju Xin. Research on regional cultural inheritance of folk houses in eastern Qinghai Province [D]. Xi'an University of architecture and technology, 2012

11. Fang Jingjing, yuan tongkai. Memory schema and ritual Imagination: Historical Metaphor in ancient village protection $[\mathrm{J}]$. Qinghai ethnic studies, 2019,30 (02): 92-98

12. Local chronicles Compilation Committee of Qinghai Province. Qinghai provincial Chronicles (Natural Geography) [M]. Hefei: Huangshan publishing house, 1995:166

13. Li Yanjun, Ma Ke, Yang haozhong. Discussion on architectural form and corresponding protection measures of traditional dwellings in southern Shaanxi [J]. Journal of Xi'an University of architecture and Technology (SOCIAL SCIENCE EDITION), 2012,31 (04): 35-40

14. Zhao Haifeng. Qinghai in contemporary China $[\mathrm{M}]$. Beijing: Contemporary China Press, 1991:293

15. Zhao Zongfu, Ma Chengjun. Chinese folklore Qinghai folklore [M]. Gansu people's publishing house, 2004:91

16. Wang Jun. series of Chinese folk architecture northwest folk architecture [M]. China Construction Industry Press. 2009:242

17. Hu Jing, Li Jiansheng. The historical process and internal factors of ethnic integration in Hehuang area [J]. Qinghai ethnic studies, 2018,29 (03): 147151

18. Cui Sipeng. You Er Mu Zhi: nomadic production mode and its ecological philosophy wisdom [J]. Qinghai ethnic studies, 2018,29 (03): 89-94

19. Li Qun. Chinese ancient architecture series. Qinghai ancient architecture [M]. China Construction Industry Press. 2015.12:245-246

20. Tang Zhongwei. Tourism development of Qinghai section of the Silk Road [N]. China Tourism News. 2011-07-08 (011) 